\title{
Application of New Media in Enterprise Marketing: Taking Cosmetics Enterprises as an Example
}

\author{
By Siqi Wang \& Yuqing Geng
}

Shanghai Dianji University

Abstract- With the steady development of information technology, new media plays a key role in enterprise marketing. It has very high coverage, can effectively spread the information of the enterprise, and help build enterprise culture. While promoting the innovation and development of enterprises, precision marketing realized at a lower cost, which helps to achieve the interaction between enterprises and consumers, plays a critical role in promoting the diversification of the consumer market and promoting the economic development of enterprises.

Keywords: new media; corporate culture; precision marketing; interactive marketing; multichannel.

GJMBR-E Classification: JEL Code: M31

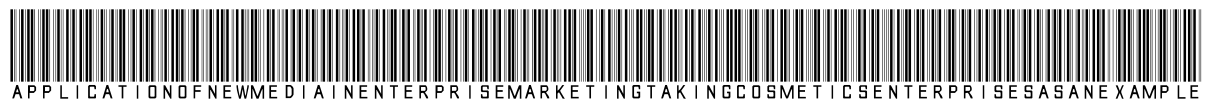

Strictly as per the compliance and regulations of:

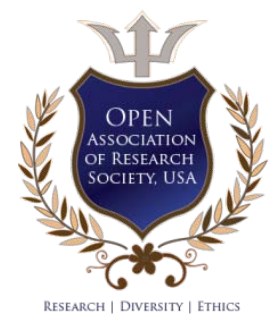

(C) 2021. Siqi Wang \& Yuqing Geng. This research/review article is distributed under the terms of the Attribution-NonCommercialNoDerivatives 4.0 International (CC BY-NC-ND 4.0). You must give appropriate credit to authors and reference this article if parts of the article are reproduced in any manner. Applicable licensing terms are at https://creativecommons.org/licenses/by-nc$\mathrm{nd} / 4.0 \%$ 


\title{
Application of New Media in Enterprise Marketing: Taking Cosmetics Enterprises as an Example
}

\author{
Siqi Wang ${ }^{\alpha} \&$ Yuqing Geng ${ }^{\sigma}$
}

Abstract- With the steady development of information technology, new media plays a key role in enterprise marketing. It has very high coverage, can effectively spread the information of the enterprise, and help build enterprise culture. While promoting the innovation and development of enterprises, precision marketing realized at a lower cost, which helps to achieve the interaction between enterprises and consumers, plays a critical role in promoting the diversification of the consumer market and promoting the economic development of enterprises.

Keywords: new media; corporate culture; precision marketing; interactive marketing; multi-channel.

\section{Current Situation And Characteristics of New Media}

W ith the rapid development of China's market and science and technology, the new media in today's society has gradually developed and expanded, constantly impacting the traditional media, and has become the mainstream way of enterprise marketing. Traditional media take newspapers and magazines as carriers or hold press conferences for publicity. In contract, new media mainly rely on hightech electronic products, such as mobile phones, tablets, computers, etc. If enterprises want to achieve better development under such circumstances, they must keep up with current events and introduce technologies related to new media. Nowadays, common new media platforms include WeChat, microblog, blogs, and even TV series or film advertising. Through these new media platforms, enterprises distribute product content to attract target customers; A communication bridge established between consumers and enterprises. Customers can receive accurate and comprehensive product information, and people can upload their experience and exchange their suggestions on products anytime and anywhere through these social platforms. Virtually, the interaction of social groups also used to promote consumers' purchase behavior and effectively spread the enterprise brand, Improved product influence. These aspects have contributed to its large audience, fast information transmission, and clear and understandable product display. New media helps break the restrictions of time and space to exchange information, covering almost all Internet users, and directly display the information you want to convey in front of the target customers with the help of words,

Author: School of Business, Shanghai Dianji University, Shanghai, China.e-mail: 1019675524@qq.com pictures, audio, or video; it integrates the advantages of various media, meets the needs of enterprises and gives full play to its superiority.

\section{The Role of New Media in the Construction of Corporate Culture}

The rapid development of the Internet has changed the media of information dissemination, and the speed of information transmission is also increasing. The opening of new media can help enterprises establish a perfect corporate culture system, strengthen cultural publicity, and show the public various of product series concepts. In today's society, people closely connect with new media. Enterprises can use these platforms to export their corporate culture to the public, and even employees, condense the hearts of employees and make them feel a strong appeal. This appeal not only gives guidance to the growth and positive development of employees but also shapes a good image of the enterprise, makes the public deeply impressed with the brand and promotes purchase behavior, Promoted the enterprise economy. Around 2017, the perfect diary put advertisements on The Red Book, an emerging app with only 50 million users, to seize the flow outlet at the initial stage of The Red Book. As early as 2017, Huaxizi also noticed that Li Jiaqi, who had not become famous by borrowing the slogan "Buy it!", had data indicating that the monthly sales of products that had been on Li Jiaqi's live broadcasting room were double those that had not broadcast marketing ${ }^{[1]}$.

\section{Iil. Advantages of Social Media in EnTERPRISE MARKETING}

a) Achieve precision marketing (accurate communication and brand building)

Users need to register their personal information before using social media. After processing of these data, users can be divided into different customer groups according to their respective gender, interests, educational level, or style type. Enterprises can understand their preferences for diverse customer groups and provide personalized services to meet their needs; through new media, enterprises can select target customers and build the brand image desired by customers. In addition, the accuracy of social media reflected in the accuracy of communication. For 
individuals, they will push product information, or promotion notices that customers are interested in recently to attract purchases, which improves the publicity effect and promotes consumption to boost corporate profits ${ }^{[2]}$. For example, in the little red book, when a user has searched for information about his skin, the brand will simply deliver products suitable for this kind of skin to attract customers to click, which will raise the marketing success rate.

\section{b) Marketing Cost Reduction}

Compared with traditional media, such as TV and radio, enterprises may not achieve a matching marketing effect when they need to invest a high capital cost. Many interference factors will accompany the short advertising time. People will not focus on advertising or implantation and also need to bear the risk of changing channels and closing electronic products. Tiktok can help reduce the cost of marketing, and much social software can release articles freely to attract people, such as short videos and WeChat official accounts. Users can also use the social platform to password of mouth, which is more effective in promoting publicity and saving related expenses.

\section{c) Realize Interactive Marketing}

Another thing worth mentioning about social media is its interactivity. Compared with traditional media, enterprises can only output brand information to customers unilaterally. In contract, the emergence of new media has realized barrier-free two-way communication between enterprises and customers and has become a convenient communication platform to understand users' behavior on the platform accurately and efficiently collect consumers' opinions and carry out internal improvement and rectification. Such a long-term communication relationship can enhance the sense of customer experience, have a sense of participation, shorten the distance with customers to establish customer loyalty and realize word-of-mouth marketing. For example, domestic cosmetics brands such as Perfect diary or Huaxizi often carry out live broadcasting activities on Taobao, intuitively display products through model makeup trials, and can know customers' questions or suggestions in real-time through bullet screens and comments, answer and record product shortcomings, and help with product innovation in the future. In July 2020, Estee Lauder held an interactive marketing activity of "Fresh surprise - One-touch burst." By using SNS invitation and gift lucky draw, users can share and invite friends to participate to obtain their fortunate draw opportunities and win a small sample of Estee Lauder's popular star product "red pomegranate". In one month, the activity attracted 1.31 million people and interactive marketing was successfully realized ${ }^{[3]}$.

\section{Analysis of Problems in the Application of Social Media in ENTERPRISE MARKETING}

\section{a) Lack of Marketing Talents}

As the staff of new media marketing, they not only need to be proficient in the professional skills of marketing but also need to master the knowledge of new media operation, which is undoubtedly a new difficulty for marketing personnel. Therefore, at present, the shortage of marketing talents is a main problem in the application of new media in enterprise marketing. In cosmetics enterprises, marketers who do not have the skills to operate social media cannot keep pace with the times. They need to keenly grasp the selling points in real-time explosive points for marketing and rely on platforms such as The Red Book and microblog for publicity to create high sales.

\section{b) Functional Defects of Marketing Platform}

The new media marketing platform is the main publicity channel and sales platform for cosmetics enterprises to sell products, and the marketing platform also has some functional deficiencies. New media not only provides consumers with freedom of communication but also brings some risks. Many speeches can release without review, and there are many wrong guide links. This negative information will damage the corporate image, which also furnish an occasion for some competitors to create public opinion to slander their peers; Moreover, on today's new media platform, the technical development of software or website is not perfect. The emergence of many junk video advertisements will lead to problems such as jamming and unsmooth broadcasting, which will affect customers' mood, reduce their purchase desire, and give up their purchase behavior ${ }^{[4]}$.

\section{c) Multiple Channels cannot Cooperate Closely}

In the past, enterprises carried out more offline store sales, but today, in addition to traditional social media, new media has also been born. Multi-channel sales make enterprises unable to combine well, and users will not know which way to choose for purchase, which will often be in trouble and finally abandon the purchase.

\section{Solutions to Problems in the Application of Social Media in EnTERPRise MARKETING}

\section{a) Training Marketing Talents}

(1) Big data processing capability. The Internet-based social platform provides customers with a wide choice space. Their subsequent actions after purchasing a product often reflect their attitude towards the product. With the help of the big data 
provided by the background, marketers need to learn how to improve through data mining. Enterprises need to set up relevant training courses to exercise employees' data analysis ability to help them understand customers' demand for products and meet the consumption habits of young people in the new era.

(2) Help employees become proficient in using social media. New media marketing is a sales activity based on a social media platform and is the basis of today's marketing. Therefore, enterprise employees must learn to skillfully use such software and websites to help customers buy and solve customers' questions.

(3) Urge employees to pay attention to current affairs and hot spots. In addition to paying attention to 4E: experience, expense, e-shop and exhibition, we should also pay more attention to some recent events and respond carefully and timely, so that we can seize the hot spots or traffic stars to carry out marketing activities and make good use of the "fan economy" to help enterprises obtain profits.

(4) Regular assessment. At the same time as training, the assessment link is also essential. The assessment link set up regularly to check the mastery of new media marketing of enterprise personnel, pay attention to their education, timely check deficiencies and fill gaps, stimulate the enthusiasm of staff to learn actively, and cultivate high-quality marketing talents.

b) Improve the Function of the Marketing Platform

(1) We should improve the audit link of the new media marketing platform. For some malicious remarks, enterprises should strangle them in the cradle, prohibit such information from being published, set up an audit team, or set keywords in the system for screening.

(2) Enterprises should have professional electronic information personnel to ensure the stabilization of the platform, ensure the smooth pop-up of advertisements and video playback, and avoid background collapse, resulting in enterprise losses, especially in large shopping festivals such as double 11.

(3) Provide various data support for major we media in the background, such as "video playback time," "views," "fan conversion rate," "product purchase rate," etc., and provide technical support for their future output, which will also benefit enterprises.

c) Closely Cooperate with Multi-Channel

(1) Realize the combination of traditional media and new media, publish the purchase channels of new media social platforms in magazines, newspapers, or TV advertisements, such as displaying QR codes for everyone to scan, and make use of the communication advantages of traditional media to improve the effectiveness of enterprise information communication. Traditional media and new media work together to maximize publicity.

(2) Enterprises must closely combine the resources of various platforms to play the greatest role. Renren.com and other social networks such as micro-blog, $Q Q$ have the ability to share. The enterprise can use several platforms to maximize publicity and marketing, just as Estee Lauder launched its first official website and Renren network in July 2020 and has attracted the attention of millions of white-collar women.

(3) In addition to online cooperation, the offline operation is also very crucial. The development of stores can provide users with trial opportunities. Offline "experiential marketing" can make customers feel the efficacy of products more truly and intuitively, make purchase decisions quickly and achieve high satisfaction ${ }^{[5]}$. In 2021, perfect diary not only retained the original online sales channel but also launched offline stores. Consumers can buy online at a more favorable price after a trial in physical stores, which virtually deepened their impression of products and increased sales and customer satisfaction. On the other hand, the colorist toner of domestic beauty makeup is the first brand to conduct live broadcasting in offline stores. While teaching consumers beauty skills through live broadcasting, it uses the heat of live broadcasting to bring offline customer traffic and achieve a winwin situation.

\section{References Références Referencias}

1. Honglin Sun. The Application of New Media in Enterprise Culture Construction [J]. New Economy, 2021, (7): 2. (in Chinese).

2. Kun Wang. Integrated Marketing Communication Value Analysis of New Media [J]. Marketing Management Review, 2021, (4): 2. (in Chinese).

3. Hongxia Wang. Estee Lauder's SNS experience marketing [J]. China Advertising, 2010, (010):150151. (in Chinese).

4. Xianlan Li. Analysis of Marketing Strategies of Enterprises Under New Media Environment [J]. Business Culture, 2021, (6): 2. (in Chinese).

5. Meifeng Xie. Research on the Application of Social Media in Enterprise Marketing [J]. Modern Business, 2020, 586(33): 39-40. (in Chinese). 